\title{
Studi Kapasitas Saluran Drainase pada Area Pemukiman ( Studi Kasus Jl. Granit Nila, Driyorejo )
}

\author{
Rizki Nurwahyudi $^{1^{*}}$, Jenny Caroline ${ }^{1}$ \\ ${ }^{1}$ Program Studi Teknik Sipil, Fakultas Teknik Sipil dan Perencanaan, Institut Teknologi Adhi Tama Surabaya \\ Emai: * $\underline{\text { rizkiaslen11@gmail.com }}$
}

\begin{abstract}
Granit Nila road located in Gresik City always gets paddle every rainy season. To investigate the flood discharge plan per channel, the capacity of the existing channels must be analyzed and then compare them with the discharge calculated using rational method. As a result, the calculation of rainfall obtained return periods of 2 years, 5 years, and 10 years by $86.12 \mathrm{~mm}, 102.57 \mathrm{~mm}$, and $109.9 \mathrm{~mm}$ consecutively. These results would then be used for calculating the sum of rain water discharge and rain water runoff discharge to get flood discharge plan. The results of evaluation upon the existing channels capacities indicated that the drainage channels could not afford the existing rain water and runoff discharge, thereby causing puddle at the research site. In terms of tertiary channel, the biggest overflow occurred in channel GN'T 5 by $1.234 \mathrm{m3} / \mathrm{second}$, while the channel only could accommodate discharge $0.198 \mathrm{~m} 3 /$ second. Meanwhile, the secondary channel GN'S 9 could support discharge $0.543 \mathrm{m3} / \mathrm{second}$, whereas the existing overflow was 3.697 $\mathrm{m} 3 / \mathrm{second}$. Finally, the calculation results of flood discharge plan demonstrated that channels GN'T $1=0.616$, GN'T $2=0.686 \mathrm{m3} / \mathrm{dt}$, GN'T $3=0.579 \mathrm{m3} / \mathrm{dt}$, GN'T $4=0.543 \mathrm{m3} / \mathrm{dt}$, GN'T $5=$ $1.234 \mathrm{m3} / \mathrm{dt}$, GN'T $6=1.177 \mathrm{m3} / \mathrm{dt}$, GN'T $7=0.295 \mathrm{m3} / \mathrm{dt}$, GN'T $8=0.961 \mathrm{m3} / \mathrm{dt}$ dan $G N^{\prime} \mathrm{S} 9=$ $3.697 \mathrm{~m} 3 / \mathrm{dt}$, consequently, the channels could afford the existing flood discharge.
\end{abstract}

Keywords: puddle, flood, drainage, channel, runoff

\begin{abstract}
Abstrak
Jl. Granit Nila berada pada wilayah Kota Gresik, merupakan kawasan pada setiap musim penghujan selalu terjadi genangan air. Dilakukan analisa perhitungan kapasitas saluran eksisting dan membandingkanya dengan debit yang dihitung menggunakan metode rasional untuk mengetahui debit banjir rencana setiap saluran. Didapatkan hasil perhitungan curah hujan rencana periode ulang 2 tahun sebesar $86,12 \mathrm{~mm}$, periode ulang 5 tahun sebesar $102,57 \mathrm{~mm}$ dan periode ulang 10 tahun sebesar 109,9 mm, yang akan digunakan sebagai perhitungan debit air hujan dan debit air hujan Limpasan kemudia dijumlah sebagai debit banjir rencana. Dari perhitungan evaluasi kapasitas saluran eksisting, didapatkan hasil bahwa saluran drainase tidak dapat menampung debit curah hujan serta limpasan yang terjadi, sehingga mengakibatkan genangan pada lokasi studi yang diteliti. Untuk saluran tersier yang mengalami luapan paling besar terjadi pada saluran GN'T 5 sebesar 1,234 m³/dt sedangkan saluran hanya dapat menampung debit sebesar $0,198 \mathrm{~m}^{3} / \mathrm{dt}$, sedangkan saluran sekunder GN'S 9 hanya bisa menampung debit sebesar $0,543 \mathrm{~m}^{3} / \mathrm{dt}$ sedangkan luapan yang terjadi sebesar 3,697 $\mathrm{m}^{3} / \mathrm{dt}$. Didapatkan hasil perhitungan debit banjir rencana pada saluran GN'T $1=0,616$, GN'T $2=0,686 \mathrm{~m}^{3} / \mathrm{dt}$, GN'T $3=0,579 \mathrm{~m}^{3} / \mathrm{dt}$, GN'T $4=0,543 \mathrm{~m}^{3} / \mathrm{dt}$, GN'T $5=1,234 \mathrm{~m}^{3} / \mathrm{dt}$, GN'T $6=$ $1,177 \mathrm{~m}^{3} / \mathrm{dt}$, GN'T $7=0,295 \mathrm{~m}^{3} / \mathrm{dt}$, GN'T $8=0,961 \mathrm{~m}^{3} / \mathrm{dt}$ dan GN'S $9=3,697 \mathrm{~m}^{3} / \mathrm{dt}$ sehingga saluran dapat menampung debit banjir yang terjadi.
\end{abstract}

Kata kunci: Genangan, Banjir, Drainase, Saluran, Limpasan. 


\section{Pendahuluan}

Intensitas curah hujan adalah jumlah curah hujan yang dinyatakan dalam tinggi hujan atau volume hujan tiap satuan waktu, yang terjadi pada satu kurun waktu air hujan terkonsentrasi [1]. Curah hujan yang tinggi bisa mengakibatkan genangan disuatu daerah, Genangan sendiri merupakan air yang berhenti mengalir pada suatu area tertentu yang bukan merupakan badan air atau tempat air. Maka untuk menghindari terjadinya genangan, manusia membuat sebuah sistem jaringan yang disebut jaringan drainase untuk mengatasi permasalahan genangan yang terjadi. Drainase mempunyai arti mengalirkan, menguras atau membuang air [2].

Secara umum, drainase didefinisikan sebagai rangkaian bangunan air dari suatu Kawasan atau lahan. Sedangkan drainase perkotaan merupakan ilmu drainase yang khusus untuk pengkajian pada kawasan perkotaan yang erat hubunganya dengan kondisi lingkungan sosial-budaya [3]. Kota Gresik merupakan kawasan yang sering terjadi genangan, salah satunya wilayah Jl. Granit Nila, Kelurahan petiken, Kecamatan Driyorejo. Genangan terjadi dikarenakan adanya perbedaan elevasi di beberapa titik, air limpasan dari daerah yang elevasinya lebih tinggi mengalir ke daerah yang elevasinya lebih rendah sehingga pada bagian elevasi yang rendah menjadi sumber tampungan air. Limpasan memiliki arti aliran air mengalir pada permukaan tanah yang ditimbulkan oleh curah hujan setelah air mengalami infiltrasi dan evaporasi [4]. Selain adanya perbedaan elevasi, sistem drainase pada area Jl. Granit Nila juga tidak berfungsi dengan baik.

\section{Metode}

Penelitian dilakukan di wilayah Jl. Granit Nila, Kota Baru Driyorejo, Gresik. Didapatkan data saluran eksisting sepanjang $1270 \mathrm{~m}$ dengan dua tipe saluran, yang pertama saluran tersier sepanjang $1060 \mathrm{~m}$ dan yang kedua saluran sekunder sepanjang $210 \mathrm{~m}$. Perhitungan menggunakan uji distribusi Log Pearson Type III dengan periode ulang 2, 5, 10 tahunan dan debit yang dihitung menggunakan metode rasional untuk mengetahui debit banjir rencana setiap saluran. Untuk data curah hujan didapatkan dari Dinas Pekerjaan Umum Sumber Daya Air Provinsi Jawa Timur, dengan menggunakan data curah hujan dari dua stasiun hujan, yaitu stasiun hujan wilayah menganti dan wilayah krikilan.

\section{Hasil dan Pembahasan}

\subsection{Analisis Hujan Rancangan}

Berdasarkan tabel 1 didapatkan rata-rata hujan maximum pertahunya sebesar 84,85 mm/dt, dan dari tabel 2 didapatkan data intensitas hujan berdasarkan periode ulang 2, 5 dan 10 tahunan.

Tabel 1. Data Curah Hujan

\begin{tabular}{ccccc}
\hline No & Tahun & $\begin{array}{c}\text { Krikilan } \\
(\mathbf{m m} / \mathbf{d t})\end{array}$ & $\begin{array}{c}\text { Menganti } \\
(\mathbf{m m} / \mathbf{d t})\end{array}$ & $\begin{array}{c}\text { Hujan } \\
(\mathbf{M a x}) \\
(\mathbf{m m} / \mathbf{d t})\end{array}$ \\
\hline 1 & 2010 & 92 & & 93,5 \\
2 & 2011 & 73 & 95 & 73 \\
3 & 2012 & 110 & 73 & 88,5 \\
4 & 2013 & 102 & 67 & 115 \\
5 & 2014 & 35 & 128 & 81,5 \\
6 & 2015 & 90 & 130 & 65 \\
7 & 2016 & 106 & 40 & 98 \\
8 & 2017 & 77 & 90 & 78,5 \\
9 & 2018 & 57 & 80 & 48,5 \\
10 & 2019 & 88 & 40 & 89,5 \\
\hline
\end{tabular}

Tabel 2. Data Curah Hujan

\begin{tabular}{ccccc}
\hline $\begin{array}{c}\text { Periode Ulang } \\
\text { Kemencengan }\end{array}$ & Koefisien (Cs) & Probabilitas (K) & $\begin{array}{c}\text { Standar Deviasi } \\
\text { (Sd) }\end{array}$ & Intensitas Hujan \\
\hline 2 & 2 & 0,164 & 0,11 & 84,72 \\
5 & 2 & 0,852 & 0,11 & 100,93 \\
10 & 2 & 1,128 & 0,11 & 108,14 \\
\hline
\end{tabular}




\subsection{Uji Distribusi Frekuensi}

Uji distribusi frekuensi bertujuan untuk mengetahui apakah jenis distribusi yang dipilih sesuai dengan data yang ada atau tidak, cara pengujian menggunakan metode uji Chi - Kuadrat dan uji Smirnov - Kolmogorof. Perhitungan Uji Chi - Kuadrat akan diterima apabila nilai Chi - Kuadrat teoritis > Nilai Chi - Kuadrat hitung. Dari perhitungan yang diperoleh didapatkan nilai Chi - Kuadrat teoritis 5,991 > nilai Chi - Kuadrat hitung 1, sehingga perhitungan diterima. Sedangkan dari perhitungan Uji Smirnov Kolmogorof diperoleh nilai Dmax $=0,061$ dengan derajat kepercayaan $=5$

$\%$ dan banyaknya data $=10$, maka diperoleh nilai Do $=0.41$. Didapatkan nilai Dmax $0,061<$ Do 0,41, maka persamaan distribusi dapat diterima.

\subsection{Analisa Waktu Konsentrasi}

Analisa waktu konsentrasi menggunakan rumus $\mathrm{Tc}=$ To (Waktu yang dibutuhkan untuk mengalir di permukaan untuk mencapai inlet) + Tf (Waktu yang dibutuhkan untuk mengalir di sepanjang saluran untuk mencapai outlet), dengan denah pembagian luasan tiap segment saluran dapat dilihat pada gambar 1, hasil To pada tabel 3, hasil tf pada tabel 4, dan hasil Tc pada Tabel 5.

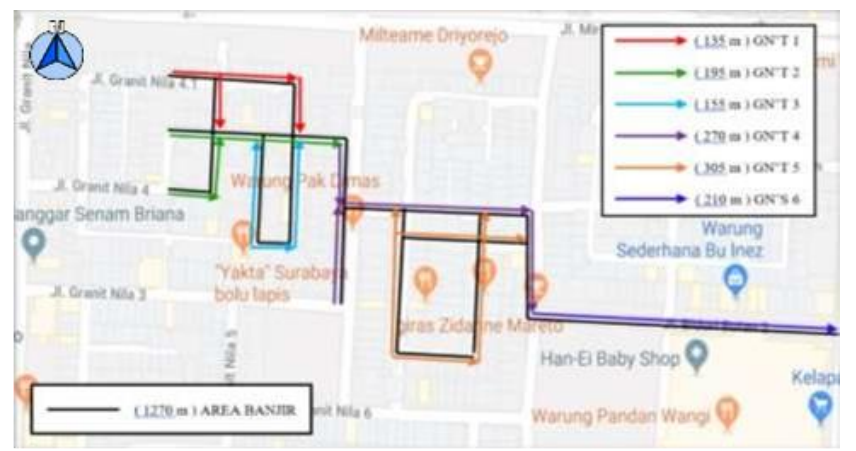

Gambar 1. Denah Luasan Area

Tabel 3. Perhitungan To

\begin{tabular}{ccccc}
\hline No & Nama Saluran & $\begin{array}{c}\text { Jarak aliran dari } \\
\text { Permukaan Tanah } \\
(\mathbf{m})\end{array}$ & $\begin{array}{c}\text { Kemiringan Dasar } \\
\text { Saluran } \\
(\boldsymbol{\%})\end{array}$ & $\mathbf{T}_{\mathbf{0}}$ \\
\hline 1 & & 3 & 0,0074 & 1,296 \\
2 & GN'T 1 & 3 & 0,0320 & 0,624 \\
3 & GN'T 2 & 3 & 0,0571 & 0,467 \\
4 & GN'T 3 & 3 & 0,0258 & 0,695 \\
5 & GN'T 4 & 4 & 0,0400 & 0,744 \\
6 & GN'T 5 & 3 & 0,0154 & 0,900 \\
7 & GN'T 6 & 3 & 0,0032 & 1,964 \\
8 & GN'T 7 & 4 & 0,0500 & 0,665 \\
9 & GN'T 8 & 4 & 0,0138 & 1,267 \\
\hline
\end{tabular}

Tabel 4. Perhitungan $T_{f}$

\begin{tabular}{ccccc}
\hline No & Nama Saluran & $\begin{array}{c}\text { Panjang Saluran } \\
(\mathbf{m})\end{array}$ & Rumus Manning & $\mathbf{T}_{\mathbf{f}}$ \\
& & & & $(\mathbf{m} / \mathbf{d t})$ \\
\hline 1 & GN'T 1 & 135 & 1,225 & 1,225 \\
2 & GN'T 2 & 125 & 2,546 & 2,546 \\
3 & GN'T 3 & 70 & 3,403 & 2,403 \\
4 & GN'T 4 & 155 & 2,287 & 2,847 \\
5 & GN'T 5 & 100 & 2,847 & 1,766 \\
6 & GN'T 6 & 310 & 1,766 & 0,809 \\
7 & GN'T 7 & 40 & 0,809 & 3,183 \\
8 & GN'T 8 & 290 & 3,183 & 2,128 \\
\hline
\end{tabular}


Tabel 5. Perhitungan $T_{c}$

\begin{tabular}{ccccc}
\hline No & Nama Saluran & $\begin{array}{c}\mathbf{T}_{\mathbf{0}} \\
\text { (menit) }\end{array}$ & $\begin{array}{c}\mathbf{T}_{\mathbf{f}} \\
\text { (menit) }\end{array}$ & $\begin{array}{c}\mathbf{T}_{\mathbf{c}} \\
\text { (menit) }\end{array}$ \\
\hline 1 & GN'T 1 & 1,296 & 1,836 & 3,133 \\
2 & GN'T 2 & 0,624 & 0,818 & 1,442 \\
3 & GN'T 3 & 0,467 & 0,343 & 0,810 \\
4 & GN'T 4 & 0,695 & 1,130 & 1,824 \\
5 & GN'T 5 & 0,744 & 0,585 & 1,329 \\
6 & GN'T 6 & 0,900 & 1,841 & 2,740 \\
7 & GN'T 7 & 1,964 & 6,390 & 8,355 \\
8 & GN'T 8 & 0,665 & 0,209 & 0,875 \\
9 & GN'S 9 & 1,267 & 2,272 & 3,538 \\
\hline
\end{tabular}

\subsection{Perhitungan Intensitas Hujan}

Intensitas hujan adalah jumlah hujan per satuan waktu yang biasanya dinyatakan dalam $\mathrm{mm} / \mathrm{jam}$ [2]. Distribusi intensitas hujan digunakan sebagai perencanaan seperti perhitungan banjir rencana, drainase, dan erosi tanah. Rumus yang digunakan dalam perhitungan rasional ialah rumus Mononobe, dengan periode ulang 2, 5 dan 10 tahunan, didapatkan hasil pada tabel 6.

Tabel 6. Intensitas Hujan

\begin{tabular}{|c|c|c|c|c|c|c|c|c|}
\hline \multirow[t]{2}{*}{ No } & \multirow{2}{*}{$\begin{array}{c}\text { Saluran } \\
\text { Pembuangan }\end{array}$} & \multicolumn{2}{|c|}{ Saluran } & \multicolumn{2}{|c|}{ Tc } & \multicolumn{3}{|c|}{ I (mm/jam) } \\
\hline & & $\begin{array}{c}\text { Bentuk } \\
\text { Saluran }\end{array}$ & $\begin{array}{c}\text { Panjang } \\
(\mathrm{m})\end{array}$ & Menit & Jam & $\begin{array}{c}\mathbf{R}_{2} \\
84,72 \\
\end{array}$ & $\begin{array}{c}R_{5} \\
100,93 \\
\end{array}$ & $\begin{array}{c}R_{10} \\
108,14 \\
\end{array}$ \\
\hline 1 & GN'T 1 & Persegi & 135 & 3,133 & 0.052 & 210,67 & 250,98 & 268,91 \\
\hline 2 & GN'T 2 & Persegi & 125 & 1,442 & 0.024 & 353,51 & 421,15 & 451,24 \\
\hline 3 & GN'T 3 & Persegi & 70 & 0,810 & 0.013 & 519,50 & 618,90 & 663,11 \\
\hline 4 & GN'T 4 & Persegi & 155 & 1,824 & 0.030 & 302,18 & 360,00 & 385,71 \\
\hline 5 & GN'T 5 & Persegi & 100 & 1,329 & 0.022 & 373,22 & 444,62 & 476,39 \\
\hline 6 & GN'T 6 & Persegi & 195 & 2,740 & 0.046 & 230,36 & 274,43 & 294,04 \\
\hline 7 & GN'T 7 & Persegi & 310 & 8,355 & 0.139 & 109,51 & 130,47 & 139,79 \\
\hline 8 & GN'T 8 & Persegi & 40 & 0,875 & 0.015 & 493,36 & 587,76 & 629,75 \\
\hline 9 & GN'S 9 & Persegi & 290 & 3,538 & 0.059 & 194,25 & 231,42 & 247,95 \\
\hline
\end{tabular}

\subsection{Perhitungan Debit Rencana}

Perhitungan debit rencana dibagi menjadi dua luasan daerah, yaitu daerah aliran sungai dan daerah limpasan yang berada pada gambar 2, dengan data luasan tiap segment daerah pada tabel 7 . Untuk perhitungan debit banjir rencana juga dibagi menjadi dua wilayah, sesuai dua luasan daerah, yang pertama debit air hujan yang menggunakan luasan daerah aliran sungai pada tabel 8, debit air hujan limpasan yang menggunakan luasan daerah limpasan pada tabel 9, dan debit banjir rencana dari penjumahan antara debit air hujan dan debit air hujan limpasan pada tabel 10.

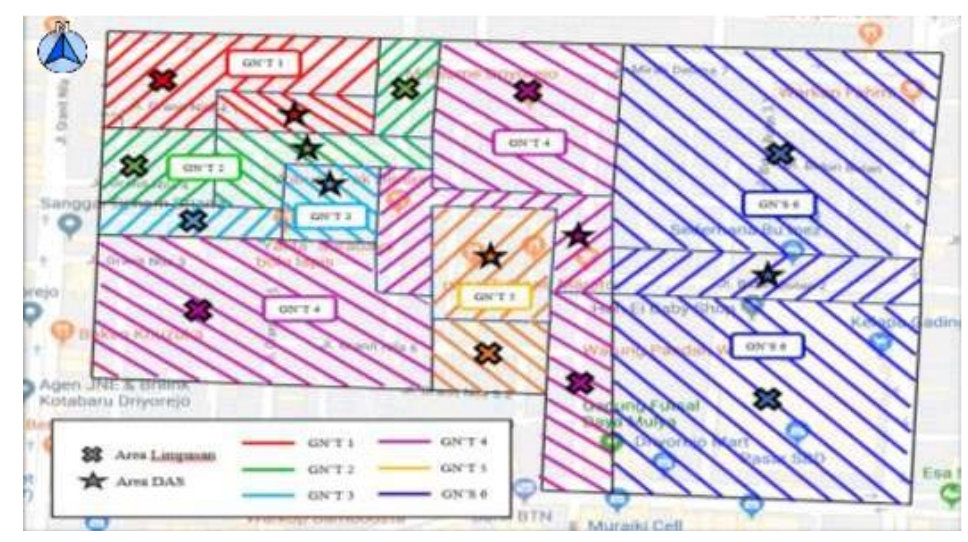

Gambar 2. Denah Lokasi Daerah Aliran Sungai dan Daerah Limpasan 
Tabel 7. Luas Wilayah Daerah Aliran Sungai dan Limpasan

\begin{tabular}{cccccc}
\hline No & $\begin{array}{c}\text { Saluran } \\
\text { Pembuangan }\end{array}$ & \multicolumn{2}{c}{ Luas Daerah Aliran } & \multicolumn{2}{c}{$\begin{array}{c}\text { Luas Daerah } \\
\text { Limpasan }\end{array}$} \\
\cline { 3 - 6 } & & $\mathbf{m 2}$ & $\mathbf{k m 2}$ & $\mathbf{m 2}$ & $\mathbf{k m 2}$ \\
\hline 1 & GN'T 1 & 2625 & 0,0026 & 7575 & 0,0075 \\
2 & GN'T 2 & 3350 & 0,0033 & 3250 & 0,0032 \\
3 & GN'T 3 & 1400 & 0,0014 & 2450 & 0,0024 \\
4 & GN'T 4 & 3250 & 0,0032 & 2875 & 0,0028 \\
5 & GN'T 5 & 5545 & 0,0055 & 5550 & 0,0056 \\
6 & GN'T 6 & 5000 & 0,005 & 12600 & 0,0126 \\
7 & GN'T 7 & 5600 & 0,0056 & 3375 & 0,0033 \\
8 & GN'T 8 & 1200 & 0,0012 & 5600 & 0,0056 \\
9 & GN'S 9 & 7000 & 0,007 & 60000 & 0,06 \\
& Total & 34970 & 0,0349 & 103275 & 0,1033 \\
\hline
\end{tabular}

Tabel 8. Perhitungan Debit Air Hujan

\begin{tabular}{|c|c|c|c|c|c|c|c|c|}
\hline \multirow[t]{2}{*}{ No } & \multirow[t]{2}{*}{$\begin{array}{c}\text { Saluran } \\
\text { Pembuangan }\end{array}$} & \multicolumn{3}{|c|}{ I (mm/jam) } & \multirow[t]{2}{*}{$\begin{array}{c}\text { Luas } \\
\text { Daerah } \\
\left(\mathbf{k m}^{2}\right)\end{array}$} & \multicolumn{3}{|c|}{$\begin{array}{l}\text { Debit Air Hujan } \\
\left(\mathrm{m}^{3} / \mathrm{dt}\right)\end{array}$} \\
\hline & & $\begin{array}{c}\mathbf{R}_{2} \\
84,72\end{array}$ & $\begin{array}{c}\mathbf{R}_{5} \\
100,93\end{array}$ & $\begin{array}{c}\mathbf{R}_{10} \\
\mathbf{1 0 8 , 1 4}\end{array}$ & & $\mathbf{Q}_{\mathrm{h} 2}$ & $\mathbf{Q}_{\mathrm{h} 5}$ & $\overline{Q_{h 10}}$ \\
\hline 1 & GN'T 1 & 210,67 & 250,98 & 268,91 & 0,0026 & 0,136 & 0,161 & 0,173 \\
\hline 2 & GN'T 2 & 353,51 & 421,15 & 451,24 & 0,0033 & 0,289 & 0,344 & 0,368 \\
\hline 3 & GN'T 3 & 519,50 & 618,90 & 663,11 & 0,0014 & 0,180 & 0,214 & 0,230 \\
\hline 4 & GN'T 4 & 302,18 & 360,00 & 385,71 & 0,0032 & 0,239 & 0,285 & 0,305 \\
\hline 5 & GN'T 5 & 373,22 & 444,62 & 476,39 & 0,0055 & 0,508 & 0,605 & 0,648 \\
\hline 6 & GN'T 6 & 230,36 & 274,43 & 294,04 & 0,005 & 0,28 & 0,34 & 0,36 \\
\hline 7 & GN'T 7 & 109,51 & 130,47 & 139,79 & 0,0056 & 0,152 & 0,181 & 0,194 \\
\hline 8 & GN'T 8 & 493,36 & 587,76 & 629,75 & 0,0012 & 0,146 & 0,175 & 0,187 \\
\hline 9 & GN'S 9 & 194,25 & 231,42 & 247,95 & 0,007 & 0,34 & 0,40 & 0,43 \\
\hline
\end{tabular}

Tabel 9. Perhitungan Debit Air Hujan Limpasan

\begin{tabular}{|c|c|c|c|c|c|c|c|c|}
\hline \multirow{3}{*}{ Saluran } & \multirow{3}{*}{ C } & \multicolumn{3}{|c|}{ Intensitas Hujan ( mm/jam ) } & \multirow{2}{*}{$\begin{array}{c}\text { Luas } \\
\text { Daerah } \\
\text { (A) }\end{array}$} & \multirow{2}{*}{$\begin{array}{c}\text { Debit Air } \\
\text { Limpasan } \\
(\mathrm{Ql} 2)\end{array}$} & \multirow{2}{*}{$\begin{array}{c}\text { Debit Air } \\
\text { Limpasan } \\
\left(\mathrm{Q} 1_{5}\right)\end{array}$} & \multirow{2}{*}{$\begin{array}{c}\begin{array}{c}\text { Debit Air } \\
\text { Limpasan }\end{array} \\
\left(\mathrm{Ql}_{10}\right)\end{array}$} \\
\hline & & $\overline{\mathrm{R}_{2}}$ & R5 & $\mathrm{R} 10$ & & & & \\
\hline & & 86,12 & 102,57 & 109,9 & $\mathrm{~km}^{2}$ & & $\mathrm{~m}^{3} / \mathrm{dt}$ & \\
\hline GN'T 1 & 0,79 & 210,67 & 250,98 & 268,91 & 0,0075 & 0,347 & 0,413 & 0,443 \\
\hline GN'T 2 & 0,79 & 353,51 & 421,15 & 451,24 & 0,0032 & 0,248 & 0,296 & 0,317 \\
\hline GN'T 3 & 0,79 & 519,50 & 618,90 & 663,11 & 0,0024 & 0,274 & 0,326 & 0,350 \\
\hline GN'T 4 & 0,79 & 302,18 & 360,00 & 385,71 & 0,0028 & 0,186 & 0,221 & 0,237 \\
\hline GN'T 5 & 0,79 & 373,22 & 444,62 & 476,39 & 0,0056 & 0,459 & 0,547 & 0,586 \\
\hline GN'T 6 & 0,79 & 230,36 & 274,43 & 294,04 & 0,0126 & 0,637 & 0,759 & 0,814 \\
\hline GN'T 7 & 0,79 & 109,51 & 130,47 & 139,79 & 0,0033 & 0,079 & 0,095 & 0,101 \\
\hline GN'T 8 & 0,79 & 493,36 & 587,76 & 629,75 & 0,0056 & 0,607 & 0,723 & 0,775 \\
\hline GN'S 9 & 0,79 & 194,25 & 231,42 & 247,95 & 0,06 & 2,560 & 3,049 & 3,267 \\
\hline
\end{tabular}

Tabel 10. Perhitungan Debit Banjir Rencana

\begin{tabular}{|c|c|c|c|c|c|c|c|c|}
\hline \multicolumn{4}{|c|}{ Debit Air Hujan } & \multicolumn{2}{|c|}{ Debit Air Limpasan } & \multicolumn{3}{|c|}{ Debit Banjir Rencana } \\
\hline Qh2 & Qh5 & Qh10 & $\mathrm{Q} 12$ & Q15 & Q110 & Qr2 & $\begin{array}{c}\text { Qr } \\
5 \\
\end{array}$ & Qr10 \\
\hline & $\mathrm{n}^{3} / \mathrm{dt}$ & & & $\mathrm{m}^{3} / \mathrm{dt}$ & & & $\mathrm{m}^{3 / d}$ & \\
\hline 0,136 & 0,161 & 0,173 & 0,347 & 0,413 & 0,443 & 0,483 & 0,575 & 0,616 \\
\hline 0,289 & 0,344 & 0,368 & 0,248 & 0,296 & 0,317 & 0,537 & 0,640 & 0,686 \\
\hline 0,180 & 0,214 & 0,230 & 0,274 & 0,326 & 0,350 & 0,454 & 0,541 & 0,579 \\
\hline 0,239 & 0,285 & 0,305 & 0,186 & 0,221 & 0,237 & 0,425 & 0,506 & 0,543 \\
\hline 0,508 & 0,605 & 0,648 & 0,459 & 0,547 & 0,586 & 0,967 & 1,152 & 1,234 \\
\hline 0,28 & 0,34 & 0,36 & 0,637 & 0,759 & 0,814 & 0,922 & 1,099 & 1,177 \\
\hline 0,152 & 0,181 & 0,194 & 0,079 & 0,095 & 0,101 & 0,231 & 0,275 & 0,295 \\
\hline 0,146 & 0,175 & 0,187 & 0,607 & 0,723 & 0,775 & 0,753 & 0,897 & 0,961 \\
\hline
\end{tabular}


$0,40 \quad 0,43$

2,560

3,049

3,267

2,896

3,450

3,697

\subsection{Perhitungan Debit Saluran}

Didapatkan hasil perhitungan debit saluran semua segment tidak dapat menampung debit curah hujan yang ada sehingga mengakibatkan terjadinya genangan, hasil perhitungan dapat dilihat pada tabel 11, sedangkan solusi yang diambil untuk menangani terjadinya genangan tersebut adalah melakukan redesign saluran dengan hasil dapat dilihat pada tabel 12 .

Tabel 11. Perhitungan Kapasitas Saluran Eksisting

\begin{tabular}{|c|c|c|c|c|c|c|c|c|c|}
\hline Saluran & $\begin{array}{c}\text { Lebar } \\
\text { (b) }\end{array}$ & $\begin{array}{c}\text { Tinggi } \\
\text { (h) }\end{array}$ & $\begin{array}{l}\text { Luas } \\
\text { (A) }\end{array}$ & $\begin{array}{c}\text { Kel. } \\
\text { Basah } \\
\text { (P) }\end{array}$ & $\begin{array}{c}\text { Jari-Jari } \\
\text { Hidrolis } \\
\left(\mathbf{R}^{2 / 3}\right)\end{array}$ & $\begin{array}{c}\text { Kecepatan } \\
\text { Afifan } \\
\text { (V) }\end{array}$ & $\begin{array}{c}\text { Q } \\
\text { existing }\end{array}$ & $\begin{array}{c}\text { Q } \\
\text { terjadi }\end{array}$ & Kondisi \\
\hline & $\mathrm{m}$ & $\mathrm{m}$ & $\mathrm{m}^{2}$ & $\mathrm{~m}$ & $\mathrm{~m}$ & $\mathrm{~m} / \mathrm{dt}$ & $\mathrm{m}^{3} / \mathrm{dt}$ & $\mathrm{m}^{3} / \mathrm{dt}$ & \\
\hline GN'T 1 & GN'T 4 & 0,4 & 0,3 & 0,12 & 0,28 & 1,65 & 0,198 & 0,616 & Melebihi \\
\hline GN'T 2 & GN'T 5 & 0,4 & 0,3 & 0,12 & 0,28 & 1,65 & 0,198 & 0,686 & Melebihi \\
\hline GN'T 3 & GN'S 6 & 0,6 & 0,4 & 0,24 & 0,28 & 1,65 & 0,198 & 0,579 & Melebihi \\
\hline GN'T 4 & GN'T 4 & 0,4 & 0,3 & 0,12 & 0,28 & 1,65 & 0,198 & 0,543 & Melebihi \\
\hline GN'T 5 & GN'T 5 & 0,4 & 0,3 & 0,12 & 0,28 & 1,65 & 0,198 & 1,234 & Melebihi \\
\hline GN'S 6 & GN'S 6 & 0,6 & 0,4 & 0,24 & 0,28 & 1,65 & 0,198 & 1,177 & Melebihi \\
\hline GN'T 7 & GN'T 4 & 0,4 & 0,3 & 0,12 & 0,28 & 1,65 & 0,198 & 0,295 & Melebihi \\
\hline GN'T 8 & GN'T 5 & 0,4 & 0,3 & 0,12 & 0,28 & 1,65 & 0,198 & 0,961 & Melebihi \\
\hline GN'S 9 & GN'S 6 & 0,6 & 0,4 & 0,24 & 0,38 & 2,26 & 0,543 & 3,697 & Melebihi \\
\hline
\end{tabular}

Tabel 12. Perhitungan Redesign Saluran Eksisting

\begin{tabular}{cccccccccc}
\hline Saluran & Lebar & Tinggi & Luas & $\begin{array}{c}\text { Keliling } \\
\text { Basah }\end{array}$ & $\begin{array}{c}\text { Jari-Jari } \\
\text { Hidrolis }\end{array}$ & $\begin{array}{c}\text { Kecepatan } \\
\text { Aliran }\end{array}$ & Q & Q & Kondisi \\
\hline GN'T 1 & 0,5 & 0,5 & 0,25 & 0,9 & 0,43 & 2,50 & 0,626 & 0,616 & Aman \\
GN'T 2 & 0,6 & 0,6 & 0,36 & 1 & 0,51 & 2,98 & 1,071 & 0,686 & Aman \\
GN'T 3 & 0,5 & 0,5 & 0,25 & 0,9 & 0,43 & 2,50 & 0,626 & 0,579 & Aman \\
GN'T 4 & 0,5 & 0,5 & 0,25 & 0,9 & 0,43 & 2,50 & 0,626 & 0,543 & Aman \\
GN'T 5 & 0,6 & 0,7 & 0,42 & 1 & 0,56 & 3,30 & 1,385 & 1,234 & Aman \\
GN'S 6 & 0,5 & 0,8 & 0,4 & 0,9 & 0,58 & 3,42 & 1,370 & 1,177 & Aman \\
GN'T 4 & 0,4 & 0,4 & 0,16 & 0,8 & 0,34 & 2,01 & 0,322 & 0,295 & Aman \\
GN'T 5 & 0,6 & 0,9 & 0,54 & 1 & 0,66 & 3,90 & 2,106 & 0,961 & Aman \\
GN'S 6 & 1 & 1 & 1 & 1,4 & 0,80 & 4,70 & 4,700 & 3,697 & Aman \\
\hline
\end{tabular}

\section{Kesimpulan}

Dari perhitungan evaluasi kapasitas saluran eksisting, didapatkan hasil bahwa saluran drainase tidak dapat menampung debit curah hujan serta limpasan yang terjadi, sehingga mengakibatkan genangan pada lokasi studi yang diteliti. Untuk saluran tersier yang mengalami luapan paling besar terjadi pada saluran GN'T 5 sebesar 1,234 m3/dt sedangkan saluran hanya dapat menampung debit sebesar $0,198 \mathrm{~m} 3 / \mathrm{dt}$, untuk saluran sekunder GN'S 9 hanya bisa menampung debit sebesar $0,543 \mathrm{~m} 3 / \mathrm{dt}$ sedangkan luapan yang terjadi sebesar 3,697 m3/dt.Didapatkan hasil perhitungan debit banjir rencana pada saluran GN'T $1=0,616 \mathrm{~m} 3 / \mathrm{dt}$, GN'T $2=0,686 \mathrm{~m} 3 / \mathrm{dt}$, GN'T $3=0,579 \mathrm{~m} 3 / \mathrm{dt}$, GN'T $4=0,543$ $\mathrm{m} 3 / \mathrm{dt}$, GN'T $5=1,234 \mathrm{~m} 3 / \mathrm{dt}$, GN'T $6=1,177 \mathrm{~m} 3 / \mathrm{dt}$, GN'T $7=0,295 \mathrm{~m} 3 / \mathrm{dt}$, GN'T $8=0,961 \mathrm{~m} 3 / \mathrm{dt}$ dan GN'S $9=3,697 \mathrm{~m} 3 / \mathrm{dt}$ sehingga saluran dapat menampung debit banjir yang terjadi. Bentuk penampang saluran setiap segment menggunakan bentuk persegi dengan dimensi yang berbeda dibeberapa titik. Ukuran dimensi penampang terbesar pada saluran tersier terdapat pada saluran GN'T 8 dengan lebar $(\mathrm{b})=0,6 \mathrm{~m}$, dan tinggi $(\mathrm{h})=0,9 \mathrm{~m}$. Sedangkan pada saluran sekunder GN'S 6 lebar $(\mathrm{b})$ $=1 \mathrm{~m}$, dan tinggi $(\mathrm{h})=1 \mathrm{~m}$. 


\section{Referensi}

[1] Wesli. 2008. "Drainase Perkotaan" Yogyakarta : Graha Ilmu.

[2] Terunajaya. 2012. "Studi Pengaruh Intensitas Hujan Terhadap Genangan Banjir di Badan Jalan ( Studi Kasus di Sekitar Jalan Aksara - Medan )"

[3] Riman. 2011. "Evaluasi Sistem Drainase Perkotaan di Kawasan Kota Metropolis Surabaya" ISSN, Vol 19 (2) : 39-46.

[4] Harahap, Rusmila. 2016. "Analisis Sistem Saluran Drainase Pada Jalan Perjuangan Medan" ISSN, Vol 2 (2) : 41-49.

[5] Hadisusanto, Nugroho. 2011. “Aplikasi Hidrologi. Malang” : Jogja Mediautama

[6] Harahap, Rusmila. 2016. "Analisis Sistem Saluran Drainase Pada Jalan Perjuangan Medan" ISSN, Vol 2 (2) : 41-49.

[7] Hasmar, Halim H. A. 2002. "Drainase Perkotaan" Yogyakarta : UII Pres

[8] Romadhoni, Wahyu. 2019. "Evaluasi Kapasitas Saluran Drainase Gunung Anyar Kota Surabaya. Skripsi tidak diterbitkan. Surabaya" : Fakultas Teknik Sipil dan Perencanaan Institut Teknologi Adhi Tama Surabaya.

[9] Suripin. 2004. "Sistem Drainase Yang Berkelanjutan" Yogyakarta : Andi Offset 